\title{
The Inhibition of the Growth of Brucellas In Vitro and In Vivo by Analogues of Erythritol
}

\author{
By H. SMITH, J. D. ANDERSON AND J. KEPPIE \\ The Microbiological Research Establishment, Porton, Salisbury \\ P. W. KENT \\ Biochemistry Department, University of Oxford \\ AND G. M. TIMMIS \\ Chester Beatty Research Institute, Royal Cancer Hospital, London
}

(Received 17 June 1964)

\section{SUMMARY}

The growth of Brucella abortus, B. melitensis and B. suis in laboratory media was inhibited by several analogues of erythritol. The use of erythritol analogues in this manner was suggested by previous work on the localization of brucellas in brucellosis. The growth of $B$. abortus within bovine phagocytes was inhibited by analogues of erythritol under conditions in which streptomycin was ineffective. Although selected erythritol analogues did not eliminate brucellosis in guinea pigs, they produced a significant diminution in infection and showed no toxicity to the host.

\section{INTRODUCTION}

The treatment of human brucellosis with antibiotics and other drugs suffers from the disadvantage that large doses must be used and the relapse rate is high (Eisele, 1950; Spink, 1956; Stableforth, 1959). Undoubtedly the tendency for relapse is due to the intracellular nature of this chronic disease, which results in latent infection at sites inaccessible to the drugs. Hence, therapy against brucellosis might benefit from a drug which could attack the intracellular organism even if this drug were not as active as other antibiotics against freely growing brucellas. The possibility that analogues of erythritol might have some inhibitory action on intra- as well as extracellular brucellas was suggested by a recent investigation into the cause of the localization of brucellas in susceptible tissues of susceptible animals (cattle, goats, sheep, swine). It was shown, first in cattle, that localization of Brucella abortus in infected pregnant animals was due to the presence, in foetal but not in adult tissues, of erythritol, a growth stimulant for $B$. abortus, which was concentrated in tissues (placenta, foetal fluids, chorion) most prone to heavy infection (Smith et al. 1961, 1962a; Pearce et al. 1962; Williams, Keppie \& Smith, 1962). Later, similar observations were made relating to $B$. melitensis and $B$. suis infections in sheep, goats and pigs (Williams et al. 1963; Keppie, Williams, Witt \& Smith, 1965). On the other hand, no detectable erythritol was found in the placenta of humans, rats, rabbits or guinea pigs, which do not suffer intense placentitis in brucellosis (Keppie et al. 1965). In relation to the present paper, the main points of previous work 
were: (i) the peculiar preference of brucellas for erythritol in the presence of glucose which has been further emphasized by recent work in a defined medium (Anderson \& Smith, 1963; Anderson \& Smith, 1965); (ii) that stimulation by erythritol of the growth of $B$. abortus occurred both in vivo and within phagocytes in a system where extracellular growth of the organism had been inhibited by streptomycin (Pearce et al. 1962). These points, coupled with the relative insusceptibility of erythritol to metabolism by mammalian tissue (Batt, Dickens \& Williamson, 1960), suggested that suitable analogues of erythritol might act as antimetabolites and inhibit the growth of extra- and possibly intracellular brucellas, without being particularly toxic to the hosts, such as man, laboratory animals and non-pregnant ungulates. This paper describes the examination of a few erythritol analogues to see whether any experimental support could be gained for these hypotheses.

\section{METHODS}

Erythritol analogues. 2-Deoxy-2-fluoro-DL-erythritol and -threitol were synthesized by the methods of Taylor \& Kent (1956) and Barnett \& Kent (1963). 2-Deoxy-DL-erythritol $(( \pm)$-butane-1,2,4-triol) and $( \pm)$-butane-1,3-diol were obtained as described by Barnett \& Kent (1963), 1-deoxy-1-fluoro-DL-glycerol by the method of Gryskiewicz-Trochimowski (1947) and 6-deoxy-6-fluoro-D-galactose according to Taylor \& Kent (1958). 1,4-Dimesyl-DL-threitol, 1,4-dimesylerythritol, 1,6-dimesyl-D-mannitol (Mannitol Myleran), 2,3-diacetyl-1,4-dibromo-1,4-dideoxyDL-threitol, 2,3-dibenzoyl-1,4-dimesyl-DL-threitol, 1,2,3,4-tetramesyl-erythritol and 1,2,3,4-tetramesyl-DL-threitol were prepared by the methods of Brown \& Timmis (1961). 1,2-3,4-Dianhydro-DL-threitol (DL-butane diepoxide) was obtained by the method of Bose, Foster \& Stephens (1959), 1,4-dibromo-1,4-dideoxy-DL-threitol, 1,4-dibromo-1,4-dideoxy-erythritol and 2,3-dibromo-2,3-dideoxy-DL-threitol by the method of Feit (1960), 1,6-dibromo-1,6-dideoxy-D-mannitol by the method of Overend, Montgomery \& Wiggins (1948) and 2,6-dimesyl- $\alpha$-D-glucopyranose by the method of Mitra, Ball \& Long (1962).

1,4-Dibromo-1,4-dideoxy-2,3-dipalmitoyl-DL-threitol was prepared by Drs G. M. Timmis and S. S. Brown by the following method. Palmitoyl chloride $(11$ g.) was added dropwise, during $45 \mathrm{~min}$., to a stirred solution of 1,4-dibromo-1,4-dideoxyDL-threitol ( $5 \mathrm{~g}$.) dissolved in pyridine (100 ml.) and kept between $5^{\circ}$ and $10^{\circ}$. When the addition was complete a substantial precipitate formed. The mixture was kept at $0^{\circ}$ for $18 \mathrm{hr}$ and then mixed with water $\left(300 \mathrm{ml}\right.$.) at $0^{\circ}$. The product was collected, washed and dried in a desiccator to yield $13 \mathrm{~g}$. of crude material. Recrystallization from an equal volume mixture of methanol and acetone (approx. $150 \mathrm{ml}$.) yielded 10 g. of the pure material, m.p. 70-75 ${ }^{\circ}$ (Found: C, 59.8; $\mathrm{H}, 9 \cdot 8 ; \mathrm{Br}, 22 \cdot 4 . \mathrm{C}_{36} \mathrm{H}_{68} \mathrm{Br}_{2} \mathrm{O}_{4}$ requires $\mathrm{C}, 59 \cdot 7 ; \mathrm{H}, 9 \cdot 5 ; \mathrm{Br}, 22 \cdot 1)$.

1,4-Dimesyl-D-threitol and 1,4-dimesyl-L-threitol was generously supplied by Dr F. W. Feit (Leo Pharmaceutical Products, Denmark).

Inhibition of growth of Brucella abortus in tryptic meat broth. Sterile concentrated solutions of analogues $(0.1 \mathrm{ml}$; containing amounts equivalent to 100, 50, 25 and $10 \mu \mathrm{g} . / \mathrm{ml}$. in the final medium) were added to tryptic meat broth $(5 \mathrm{ml}$.) containing 1-10 $\times 10^{6}$ Brucella abortus $/ \mathrm{ml}$. These cultures, together with controls, were shaken at $37^{\circ}$ in $5 \% \mathrm{CO}_{2}$ in air for $24 \mathrm{hr}$ and the concentrations of organisms determined 
photometrically $(570 \mathrm{~m} \mu)$ at 16 and $24 \mathrm{hr}$. When an analogue inhibited growth, the lowest concentration of analogue which produced $50 \%$ inhibition as compared with the population of the control at $24 \mathrm{hr}$ was noted. Any material, $100 \mu \mathrm{g} . / \mathrm{ml}$. of which produced no inhibition at $24 \mathrm{hr}$, was scored as inactive.

Inhibition of growth of Brucella abortus in a defined medium containing glucose. Sterile solutions of the inhibitors $(1 \mathrm{ml} ., 5 \mu \mathrm{mole} / \mathrm{ml}$.) and the inoculated defined medium (4 ml. containing $2.5 \times 10^{7}$ Brucella abortus $/ \mathrm{ml}$.) were mixed in flasks (25 ml.) and shaken at $37^{\circ}$ in $5 \% \mathrm{CO}_{2}$ in air as described by Anderson \& Smith (1965). At various time intervals, the extinctions of the contents of duplicate flasks were compared as described by Anderson \& Smith (1965) with those of similar control samples.

Inhibition of growth of Brucella abortus within bovine phagocytes. The test was that described by Pearce et al. (1962) for testing substances which affect the growth of Brucella abortus (strain 544) within bovine phagocytes. Sterile solutions of the analogues in Locke solution $(0.5 \mathrm{ml}$; the concentrations were such that analogue at $200,100,50,25$ and $10 \mu \mathrm{g} . / \mathrm{ml}$. was present in the final mixture at incubation) were the test materials (see Pearce et al. 1962; under the heading 'Addition of test material and incubation for $40 \mathrm{hr}$ '). They were mixed with a suspension (1.3 ml.) of bovine white blood cells in which intracellular $B$. abortus (strain 544) would grow on incubation despite the fact that the suspending fluid was a mixture of fresh (bactericidal) bovine serum containing streptomycin $(2 \mu \mathrm{g} . / \mathrm{ml}$.$) . After incubation for$ $40 \mathrm{hr}$, the growth of intracellular B. abortus was estimated as described by Pearce et al. (1962). When the analogue inhibited growth, the lowest concentration of analogue which produced $50 \%$ inhibition as compared with growth in control samples was noted.

Action of analogues against Brucella abortus infection in the guinea pig. Guinea pigs were infected with Brucella abortus (strain $544 ; 1 \times 10^{4}$ organisms intramuscularly). After 7 days, the guinea pigs were treated daily with the test material injected subcutaneously and at intervals of 3,6,9 and 12 weeks groups of guinea pigs were withdrawn from the main batch, weighed, left 1 week without treatment, and then the number of organisms in their spleens estimated by the method described by Smith et al. $(1962 b)$. Comparisons were made with the infections in control animals.

Inhibition of growth of Brucella melitensis and B. suis in a laboratory medium. Various concentrations of 2-deoxy-2-fluoro-DL-erythritol and 1,4-dimesyl-DLthreitol were dissolved in a mixture of tryptic meat broth (1 ml.) and saline $(2 \mathrm{ml}$. in flasks $(25 \mathrm{ml}$.). After inoculation (100 organisms $/ \mathrm{ml}$.) the flasks were shaken at $37^{\circ}$ for $27 \mathrm{hr}$. Viable counts (see Pearce et al. 1962) indicated the inhibition of growth as compared with control samples. The lowest concentration of analogue which produced $50 \%$ inhibition was recorded.

\section{RESULTS}

The action of erythritol analogues and related compounds on the growth of Brucella abortus in tryptic digest meat broth

The results in the first column of Table 1 show that certain fluoro-, mesyl- and bromo- derivatives of erythritol and threitol inhibited the growth of Brucella 
abortus in tryptic meat broth. The lack of activity shown by fluoro-, mesyl- and bromo-derivatives of other sugars and polyols indicated the specificity of the inhibitury effect. The high activity of 1,2-3,4-dianhydro-DL-threitol was not surprising in view of the known cytotoxic action of epoxides. Apart from this epoxide, the most active materials were the 1,4-dimesyl-threitols especially the $\mathrm{L}$ compound.

Table 1. Action of erythritol analogues and related compounds on the growth of Brucella abortus in tryptic meat broth and within bovine phagocytes

Compound $\overbrace{\begin{array}{c}\text { In tryptic } \\ \text { meat broth* }\end{array}}^{\begin{array}{c}\text { Concentration of compound } \\ \text { producing } 50 \% \text { inhibition } \\ (\mu \mathrm{g} . / \mathrm{ml} .)\end{array}}$

Erythritol derivatives

$\begin{array}{llc}\text { 2-Deoxy-2-fiuoro-DL-erythritol } & 100 & 50-100 \\ \text { 1,4-Dimesyl-erythritol } & 100 & 50-100 \\ \text { 1,4-Dibromo-1,4-dideoxy-erythritol } & \text { Inactive } \dagger & - \\ \text { 2-Deoxy-DL-erythritol } & \text { Inactive } & -\end{array}$

Threitol derivatives

\begin{tabular}{|c|c|c|}
\hline 2-Deoxy-2-fluoro-DL-threitol & Inactive & Inactive \\
\hline 1,4-Dimesyl-DL-threitol & $25-50$ & 25 \\
\hline 1,4-Dimesyl-D-threitol & 50 & 100 \\
\hline 1,4-Dimesyl-L-threitol & 25 & 25 \\
\hline 1,2-3,4-Dianhydro-DL-threitol & 5 & 5 \\
\hline 1,4-Dibromo-1,4-dideoxy-DL-threitol & 100 & - \\
\hline 2,3-Dibromo-2,3-dideoxy-DL-threitol & Inactive & - \\
\hline \multicolumn{3}{|c|}{ Related compounds } \\
\hline 1,6-Dimesyl-n-mannitol & Inactive & - \\
\hline 1,6-Dibromo-1,6-dideoxy-D-mannitol & Inactive & - \\
\hline 1-Deoxy-1-fluoro-DL-glycerol & Inactive & - \\
\hline 6-Deoxy-6-fluoro-D-galactose & Inactive & Inactive \\
\hline ( \pm )-Butane-1,3-diol & Inactive & Inactive \\
\hline 2,6-Dimesyl- $\alpha$-D-glucopyranoside & Inactive & - \\
\hline
\end{tabular}

$-=$ not tested.

* For details of tests see Methods. In the test with intracellular B. abortus, 2-deoxy-2-fluoroDL-erythritol produced no toxic effects on the phagocytes (for evidence of toxicity see Pearce $e t$ al. 1962); at high concentrations the mesyl compounds and anhydro-threitol showed some toxicity, but at the concentrations used for growth inhibition no significant toxic effects were observed.

$\uparrow$ No significant inhibition at $100 \mu \mathrm{g} . / \mathrm{ml}$.

The action of erythritol analogues and related compounds on the growth of Brucella abortus within bovine phagocytes

The results in the second column of Table 1 show that the compounds which inhibited the growth of Brucella abortus in a laboratory medium also inhibited the growth of intracellular $B$. abortus. This means that, unlike the streptomycin which was present in the suspending fluid (see Methods), the inhibitory analogues penetrated into the bovine phagocytes. In the intracellular test, the relative activity of the different inhibitors was the same as their relative activity in the laboratory medium. At the concentrations tested, the compounds were without apparent deleterious effect upon the phagocytes. 
The action of erythritol analogues and related compounds on the growth of Brucella abortus in a defined medium containing an optimal amount of glucose

The results in Table 2 show that in a defined medium a representative selection of analogues produced inibition of the growth of Brucella abortus comparable with that found in tryptic meat broth and in bovine phagocytes. Furthermore, the inhibitory effects of 2-deoxy-2-fluoro-DL-erythritol and 1,4-dimesyl-DL-threitol were annulled by mixing them with an equimolar quantity of erythritol.

Table 2. The effect of erythritol analogues on the growth of Brucella abortus in a defined medium containing glucose; the effect of mixing certain inhibitors with erythritol

Analogue
$\quad(1 \mu \mathrm{mole} / \mathrm{ml}$.

\begin{tabular}{|c|c|c|}
\hline $16 \mathrm{hr}$ & $24 \mathrm{hr}$ & $40 \mathrm{hr}$ \\
\hline 70 & 62 & 37 \\
\hline 95 & 85 & 69 \\
\hline 82 & 69 & 77 \\
\hline 95 & 65 & 53 \\
\hline 85 & 73 & 56 \\
\hline 98 & 98 & 95 \\
\hline 30 & 19 & 13 \\
\hline 96 & 97 & 89 \\
\hline 100 & 95 & 96 \\
\hline 232 & $271^{*}$ & 180 \\
\hline 184 & 206 & 119 \\
\hline 222 & 204 & 139 \\
\hline
\end{tabular}

* All erythritol was used by 24-30 hr.

The effect of erythritol analogues on Brucella abortus infections in guinea pigs

The results in Table 3 show that 2-deoxy-2-fluoro-DL-erythritol, 1,4-dimesyl-DLthreitol and 1,4-dibromo-1,4-dideoxy-DL-threitol had no dramatic effect on brucellosis in guinea pigs. However, 1,4-dimesyl-DL-threitol and 1,4-dibromo-1,4dideoxy-DL-threitol produced a significant decrease (statistical analysis by our colleague Mr S. Peto) in infection and showed no evidence of toxicity for the host despite the prolonged administration. The epoxide, 1,2-3,4-dianhydro-DL-threitol, was too toxic for use as a therapeutic agent. The analogues shown in Table 3 would have been excreted rapidly, but attempts to produce an effective depot effect by using less-soluble analogues (2,3-dibenzoyl-1,4-dimesyl-oL-threitol, 2,3-diacetyl1,4-dibromo-DL-threitol, 1,2,3,4-tetramesyl-DL-threitol, 1,2,3,4-tetramesyl erythritol, 1,4-dibromo-1,4-dideoxy-2,3-dipalmitoyl-DL-threitol) were without success.

\section{The inhibitory effect of 2-deoxy-2-fluoro-DL-erythritol and 1,4-dimesyl-DL-threitol} on the growth of Brucella melitensis and B. suis in vitro

The growth in tryptic meat broth of three strains of Brucella melitensis (6015, 1374, В 115) and two strains of B. suis (KG 25, 1330) was inhibited to the extent of $50 \%$ by 1,4-dimesyl-DL-threitol (50 $\mu \mathrm{g}$. $/ \mathrm{ml}$.) and 2-deoxy-2-fluoro-DL-erythritol (100 $\mu \mathrm{g}$. $/ \mathrm{ml}$.). 
Table 3. The effect of erythritol analogues on Brucella abortus infection in guinea pigs

\begin{tabular}{|c|c|c|c|c|}
\hline \multirow[b]{2}{*}{ Examination of animals $\dagger$} & \multirow[b]{2}{*}{ Controls } & \multicolumn{3}{|c|}{ Treatment with analogues* } \\
\hline & & $\begin{array}{l}\text { 2-Deoxy-2- } \\
\text { fluoro-DL- } \\
\text { erythritol }\end{array}$ & $\begin{array}{l}\text { 1,4-Dimesyl- } \\
\text { DL-threitol }\end{array}$ & $\begin{array}{l}\text { 1,4-Dibromo- } \\
\text { 1,4-dideoxy- } \\
\text { DL-threitol }\end{array}$ \\
\hline $\begin{array}{l}\text { No. of animals examined after } \\
\text { each period of treatment }\end{array}$ & 15-20 & $\mathbf{5}$ & 10 & 10 \\
\hline $\begin{array}{l}\text { At } 3 \text { weeks } \\
\begin{aligned} \% \text { animals with spleen count } \\
\quad<\mathbf{3 0 0} \\
>\mathbf{3 0 0} \text { and }<\mathbf{1} \times \mathbf{1 0}^{6}\end{aligned}\end{array}$ & $\begin{array}{r}\mathrm{Nil} \\
60\end{array}$ & $\begin{array}{c}\text { Nil } \\
80\end{array}$ & $\begin{array}{c}\text { Nil } \\
80\end{array}$ & $\begin{array}{r}\mathrm{Nil} \\
\mathbf{8 0}\end{array}$ \\
\hline Average body weight (g.) & 575 & 570 & 540 & 540 \\
\hline $\begin{array}{l}\text { At } 6 \text { weeks } \\
\begin{aligned} \% & \text { animals with spleen count } \\
& <300 \\
& >300 \text { and }<5 \times 10^{5}\end{aligned}\end{array}$ & $\begin{array}{l}\text { Nil } \\
40\end{array}$ & - & $\begin{array}{l}30 \\
40\end{array}$ & $\begin{array}{c}\mathrm{Nil} \\
\mathbf{4 0}\end{array}$ \\
\hline Average body weight (g.) & 650 & - & 580 & 600 \\
\hline $\begin{array}{l}\text { At } 9 \text { weeks } \\
\begin{aligned} \% \text { animals with spleen counts } \\
\quad<\mathbf{3 0 0} \\
>\mathbf{3 0 0} \text { and }<5 \times 10^{4}\end{aligned}\end{array}$ & $\begin{array}{r}\text { Nil } \\
45\end{array}$ & $\begin{array}{r}\text { Nil } \\
60\end{array}$ & $\begin{array}{r}\text { Nil } \\
70\end{array}$ & $\begin{array}{l}20 \\
60\end{array}$ \\
\hline Average body weight (g.) & 700 & 720 & 620 & 650 \\
\hline $\begin{array}{l}\text { At } 12 \text { weeks } \\
\begin{array}{l}\% \text { animals with spleen count } \\
\quad<300 \\
>300 \text { and }<1 \times 10^{4}\end{array}\end{array}$ & $\begin{array}{r}25 \\
5\end{array}$ & - & $\begin{array}{l}\mathbf{5 0} \\
\mathbf{3 0}\end{array}$ & $\begin{array}{l}50 \\
40\end{array}$ \\
\hline Average body weight (g.) & 690 & - & $\mathbf{7 5 0}$ & 730 \\
\hline
\end{tabular}

* Guinea pigs, infected 7 days previously with $1 \times 10^{4} B$. abortus given intramuscularly, were treated daily for the periods stated with $10 \mathrm{mg}$. of the analogue given subcutaneously.

$\dagger$ The extent of infection in the spleen was obtained by methods described by Smith et al. $(1962 b)$.

\section{DISCUSSION}

Although only relatively few erythritol analogues have been examined in this work, the results support the hypotheses stated in the introduction to this paper. Some erythritol analogues inhibit the growth of Brucella abortus: (1) in vitro in two media; (2) within bovine phagocytes in a test in which extracellular streptomycin has no bactericidal action intracellularly; (3) in infected guinea pigs without being toxic to the host. It appears also that, like the stimulatory effect of erythritol, the inhibitory effect of erythritol analogues extends to growth of $B$. melitensis and $B$. suis. This work adds weight to the evidence of a specific relation between the carbohydrate metabolism of Brucella and erythritol. The inhibitory action of at least two of the analogues is reversed by addition of erythritol; the analogues inhibit growth, just as erythritol stimulates growth, in the presence of large and optimal amounts of glucose and usage of glucose by $\boldsymbol{B}$. abortus is decreased by addition of erythritol or 2-deoxy-2-fluoro-DL-erythritol (Anderson \& Smith, 1965). The significance of these observations will only become clear when we know more about the metabolism of erythritol by $B$. abortus.

Since relatively few analogues were available for examination, little can be said about the reasons for the relative activity of different analogues, e.g. the differences 
in activity between the 1,4- and 2,3-dibromo- derivatives of DL-threitol, the fluoroderivatives of erythritol and DL-threitol and the D- and L- forms of 1,4-dimesylthreitol. Perhaps the superior activity of the threitol over erythritol compounds is due to the fact that threitol, liberated by spontaneous hydrolysis or after alkylation of enzymes, does not, in contrast to erythritol, stimulate the growth of Brucella abortus. Also, the molecular conformation of 2-deoxy-2-fluoro-DL-erythritol bears a very close resemblance to that of erythritol so as to make a competitive mechanism likely.

It was hoped that the dimesyl- and dibromo-derivatives might be capable of some degree of irreversible inhibition. 1,6-Dimesyl-D-mannitol appears to inhibit fructose diphosphate irreversibly, an effect which was speculatively attributed to the alkylating ability of this compound (Timmis, Weber \& Singhal, 1963), which perhaps suggests a stable bond between the drug and the enzyme. Although it is not suggested that this particular enzyme is concerned in the inhibition of Brucella described here, the fact that 1,4-dimesyl-L-threitol was more active than the $D$ isomer indicates that the enzyme concerned has a type of specificity dependent upon optical isomerism of polyols, similar to fructose diphosphatase, which is not inhibited by 1,6-dimesyl-L-mannitol. Although some erythritol analogues will inhibit the intracellular growth of Brucella, no analogue so far examined is sufficiently active to be considered as a therapeutic agent. Nevertheless, sufficient work has been done to indicate that such an agent might emerge from further exploration along these lines.

Part of this work was supported by grants to the Chester Beatty Research Institute (Institute of Cancer Research: Royal Cancer Hospital) from the Medical Research Council, the British Empire Cancer Campaign and the National Cancer Institute of the National Institutes of Health, U.S. Public Health Service.

\section{REFERENCES}

Anderson, J. D. \& SMith, H. (1963). The metabolism of erythritol by a virulent strain of Brucella abortus. J. gen. Microbiol. 31, xxiii.

Anderson, J. D. \& Smith, H. (1965). The metabolism of erythritol by Brucella abortus. J. gen. Microbiol. 38, 109.

Barnet, J. E. G. \& Kent, P. W. (1963). Fluorocarbohydrates Part VI. Selective reduction of oxo-esters by potassium borohydride. J. chem. Soc. p. 2743.

BatT, R. D., Dickens, F. \& Williamson, D. H. (1960). Tetrose metabolism 2. The utilization of tetroses and tetritols by rat tissues. Biochem. J. 77, 281.

Bose, J. L., Foster, A. B. \& Stephens, R. W. (1959). Reaction of periodate with compounds containing active methylene groups. J. chem. Soc. p. 3314.

Brown, S. S. \& Trmmis, G. M. (1961). The preparation of $\alpha \omega$-di-O-methane sulphonyl derivatives of some sugar alcohols. J. chem. Soc. p. 3656 .

Eiskife, C. W. (1950). Therapy of brucellosis in man. In Brucellosis, p. 148. Ed. Larson, C. L. \& Soule, M. H. Washington: American Association for the Advancement of Science.

Feit, P. W. (1960). Synthesis of stereoisomeric butane-1,2-3,4-diepoxides. Chem. Berichte, 93, 116.

Gryskiewicz-Trochimowski, E. (1947). Recherches sur les composés organiques fluores dans la série aliphatique. Rec. Trav. chim. 66, 427.

Keppie, J., Williams, A. E., WitT, K. \& Smith, H. (1965). The role of erythritol in the tissue localization of the brucellae. Brit. J. exp. Path. (in the Press).

Mrtra, A. K., BALL, D. H. \& LONG, L. JR. (1962). Methyl 2,6-di- $O$-(methylsulfonyl)- $\alpha$-Dglucopyranoside and new synthesis of 3,4-di- and 3,4,6-tri-O-methyl-D-glucose. J. Org. Chem. 27, 160. 
Overend, W. G., Montgomery, R. \& Wrgains, L. F. (1948). Anhydrides of polyhydric alcohols Part XI. The action of phosphorus tribromide on 1,4-3,6-dianhydro-mannitol and -sorbitol. Some new chloro-derivatives of 1,4-3,6-dianhydro sorbitol. J. chem. Soc. p. 2201.

Pearce, J. H., Williams, A. E., Harris-Smith, P. W., Fitzgeorge, R. B. \& Smith, H. (1962). The chemical basis of the virulence of Brucella abortus II. Erythritol, a constituent of bovine foetal fluids which stimulates the growth of $\mathbf{B r}$. abortus in bovine phagocytes. Brit. J. exp. Path. 43, 31.

Smith, H., Keppie, J., Pearce, J. H., Fuller, R. \& Williams, A. E. (1961). The chemical basis of the virulence of Brucella abortus I. Isolation of Br. abortus from bovine foetal tissue. Brit. J. exp. Path. 42, 631.

Smith, H., Williams, A. E., Pearce, J. H., Keppie, J., Harris-Smith, P. W., FitzGEORGE, R. B. \& WITT, K. (1962a). Foetal erythritol: a cause of the localization of Brucella abortus in bovine contagious abortion. Nature, Lond. 193, 47.

Smith, H., Keppie, J., Pearce, J. H. \& Witt, K. (1962b). The chemical basis of the virulence of Brucella abortus IV. Immunogenic products from Brucella abortus grown in vivo and in vitro. Brit. J. exp. Path. 43, 538.

SpINk, W. N. (1956). The Nature of Brucellosis, p. 258. Minneapolis: The University of Minnesota Press.

Stablefonth, A. W. (1959). Brucellosis. In Infectious Diseases of Animals: Diseases due to Bacteria, p. 53. Ed. Stableforth, A. W. \& Galloway, I. A. London: Butterworth's Scientific Publications.

TAYlor, N. F. \& Kent, P. W. (1956). The synthesis of 2-deoxy-2-fluoro-tetritols and 2-deoxy-2-fluoro-( \pm )-glyceraldehyde. J. chem. Soc. p. 2150.

TAYlor, N. F. \& Kent, P. W. (1958). Fluorocarbohydrates Part I. The synthesis of 6-deoxy-6-fluoro-D-galactose and 5-deoxy-5-fluoro-D-ribose. J. chem. Soc. p. 872.

Timmis, G. M., Weber, G. \& Singhat, R. L. (1963). 1,6-Dimesyl-D-mannitol and carbohydrate metabolism. In Symposium on Regulation of Enzyme Activity and Synthesis in Normal and Neoplastic Liver, Indiana, 1962, 375. Ed. Weber, G. London: Pergamon Press.

Williams, A. E., Keppie, J. \& Smith, H. (1962). The chemical basis of the virulence of Brucella abortus III. Foetal erythritol a cause of the localisation of Brucella abortus in pregnant cows. Brit. J. exp. Path. 43, 530.

Williams, A. E., Keppie, J. \& Smith, H. (1963). Erythritol, its effect on the growth of various strains of Brucella abortus and its possible significance in infections with Brucella melitensis and Brucella suis. J. gen. Microbiol. 31, xxiii. 